\title{
Evolución de la radio global y competencia en Internet. El caso de Radio Exterior de España
}

\author{
Santiago MARTínez ARIAS \\ Universidad Complutense de Madrid \\ santiagomarias@ccinf.ucm.es \\ Alberto MARTínez ARIAS \\ Radio Exterior de España \\ mtzarias@gmail.com
}

Recibido: $12 / 03 / 2012$

Aceptado: 30/10/2012

\begin{abstract}
Resumen
La introducción de los cibermedios en el panorama empresarial de la comunicación ha supuesto un vuelco completo en el quehacer habitual de los medios tradicionales, que han tenido que adaptarse con rapidez y con toda la eficacia posible a una nueva forma de hacer periodismo. Los nuevos medios han experimentado una rápida evolución que ha producido, con cinco generaciones de cibermedios. Se estudia aquí la incidencia de este nuevo escenario global de las comunicaciones en un sector concreto de los medios audiovisuales como es la radio. Y en concreto en uno de los canales de la radio pública, Radio Exterior de España, como caso a su vez particular debido a dos características principales: su carácter global y el carácter de servicio público.
\end{abstract}

Palabras clave: Cibermedia, Radio en Internet, Medio global, Audiencia en Internet

\section{International Broadcasting Radio Evolution and Internet Concurrence. The Case of "Radio Exterior de España"}

\begin{abstract}
The new communication business landscape of the online media has supposed a complete break in the day by day of traditional media, which have had the necessity to adapt quickly and efficiently to a new journalism. The new media have undergone an evolution which has produced five generations of online media. We study here the impact of this new global status of communications, and in a particular related to the part of audiovisual media such as Radio media. Particularly in one of the public world radio channel, Radio Exterior de España, as a case in turn especially due to two main characteristics: its global nature and its character of public service.
\end{abstract}

Keywords: Cibermedia, Radio Broadcast in Internet, Global Media, Internet Audience

\section{Referencia normalizada}

MARTÍNEZ ARIAS, Santiago y MARTÍNEZ ARIAS, Alberto (2013): "Evolución de la radio global y competencia en Internet. El caso de Radio Exterior de España". Estudios sobre el mensaje periodístico. Vol. 19, Núm. 1, págs.: 487-504. Madrid, Servicio de Publicaciones de la Universidad Complutense.

Sumario: 1. Presentación. 2. Estado de la cuestión. 3. Radio en Internet o ciberradio?. 4. Internet y la radio global. El caso de Radio Exterior de España; 4.1. Orígenes y evolución de Radio Exterior de España; 4.2. La audiencia de Radio Exterior de España; 4.3. La encuesta; 4.4. Cuadros de las respuestas a la encuesta; 4.4.1. Cuadro Mundial; 4.4.2. Cuadros de las respuestas por continentes y países. 5. Conclusiones. 6. Referencias bibliográficas.

\section{Presentación}

La introducción de las nuevas tecnologías y de los cibermedios en el panorama empresarial de la comunicación ha supuesto un vuelco completo en el quehacer habitual 
de los medios tradicionales, que han tenido que adaptarse con rapidez y con toda la eficacia posible a una nueva forma de hacer periodismo. En este marco, los nuevos medios han experimentado una rápida evolución que ha producido, con cinco generaciones de cibermedios, desde los inicios de Internet a la generación de cibermedios para dispositivos móviles (smartphones y tabletas) y los periódicos bajo demanda o los cibermedios de pago. En este contexto, los medios audiovisuales han ido a la zaga de la prensa impresa, aunque la adaptación a las nuevas tecnologías distribuidas por la Red y su evolución, ha sido mucho más rápida.

Estudiaremos aquí la incidencia de este nuevo escenario global de las comunicaciones en un sector concreto de los medios audiovisuales como es la radio. $\mathrm{Y}$ en concreto en uno de los canales de la radio pública, Radio Exterior de España (a partir de ahora REE), como caso a su vez particular debido a dos características principales. La primera es su carácter global previo a la introducción de Internet, basado en la emisión por radiofrecuencias de onda corta. $\mathrm{Y}$ un segundo aspecto a tener muy en cuenta: el carácter de servicio público de la emisora y, en consecuencia, la procedencia pública de las inversiones, tanto de capital económico como humano y profesional.

Tenemos pues un caso de estudio sobre la mesa cuyo análisis es relevante por los condicionamientos citados. A la hora de establecer este estado de la cuestión, necesariamente haremos una aproximación a los estudios académicos realizados sobre la materia. Aunque encontramos con facilidad numerosos estudios e investigaciones realizados respecto a la incidencia de Internet en el sector de la comunicación, y por supuesto en la sociedad en general, es difícil encontrar estudios o investigaciones realizadas específicamente en el terreno de la radio en general, y de las radios globales -como es nuestro caso de estudio- en particular.

A continuación nuestras variables serán, necesariamente, cómo se ha hecho la adaptación a las nuevas tecnologías de un medio cuyo público objetivo ha sido ampliado exponencialmente gracias, precisamente, a la introducción del nuevo medio global, Internet. Es decir, de un lado este tipo de radio ha adaptado las nuevas tecnologías en el mercado para conservar una parte de la audiencia que sigue consumiendo el producto 'radio' a través de las radiofrecuencias de onda corta, que sigue siendo una de las principales formas de acceso a REE por buena parte de su audiencia, y que ha sufrido una evidente mejora y evolución gracias al perfeccionamiento de los medios de transmisión de la señal y, en su caso, de los equipos receptores. Por otra parte, la inclusión, al igual que otras radios comerciales o no, de la señal a través de Internet, ha supuesto también un aumento notable de su capacidad de distribución, con una mayor efectividad a la hora de sumar nuevos oyentes.

La segunda variable de estudio a tener en cuenta en esta investigación sería la medición de audiencias de radio para nuestro caso particular. La difusión de la señal de REE no ha sido nunca medida en los EGM habituales debido a las características particulares ya descritas, de forma que es imposible hacer un balance exacto de esta incidencia. Sí existen, sin embargo, estudios que realizan una aproximación al impacto de la programación en la audiencia. Hay que tener en cuenta aquí que al no tratarse de una radio comercial los índices de impacto y la inclusión dentro de diversos estudios de mercado está fuera de lugar. 
Por último en este apartado cabría señalar, atendiendo a la incidencia que podría tener la distribución de la señal de REE a través de Internet, que todavía son escasos los estudios de mercado fiables sobre audiencias en la Red. Aunque las empresas publicitarias siguen implicadas en una dura batalla por conseguir la fórmula adecuada para la medición más exacta posible de las audiencias en Internet (no sólo de radio, sino de cualquier otro medio audiovisual o escrito -sea cibermedio exclusivamente o sea prensa impresa trasladada a la pantalla de ordenador-) todavía no existe una solución estandarizada adecuada para este propósito.

Para ello utilizaremos como herramienta metodológica el análisis de una encuesta realizada recientemente por esta cadena pública, REE, en la que a través de sus distintas emisiones se ha solicitado a la audiencia la cumplimentación de un cuestionario con el objeto de conocer su perfil y, en consecuencia, mejorar la eficacia de la programación de la cadena. En los resultados de la encuesta, que reflejan datos relativos tanto a la fórmula de audiencia del medio -Internet, onda corta, podcast, satélitecomo los tipos de programas escuchados, se han incluido los instrumentos habituales de los que se vale cualquier investigación al efecto -edad, sexo, ocupación, etc.-, además de otros aspectos particulares en este caso, como referencias geográficas o franja horaria de escucha. De esos resultados extraeremos las conclusiones de la investigación, y comprobaremos cómo se han adaptado los medios públicos a las nuevas circunstancias del mercado audiovisual.

1. ¿Ha conseguido REE realizar la adaptación que exige Internet un cambio radical en la nueva forma de hacer el periodismo? Aunque las radios de ámbito internacional existentes, como es el caso de REE, han encontrado una dura competencia en el desarrollo de Internet como medio global, han sabido adaptarse a los nuevos tiempos aprovechando y conservando las antiguas fórmulas de distribución de su señal y complementándolas gracias a su adaptación y entrada paralela en el mercado de la red de redes.

2. ¿Cuál es la tipología del público objetivo de REE? Podremos atisbar cómo es el oyente de este tipo de medio, y, gracias a nuestra herramienta metodológica, hacer una descripción del perfil tipo de audiencia que utiliza este tipo de radio, tanto desde el punto de vista del servicio público como desde el objetivo de información y entretenimiento que se propone cualquier medio de comunicación de estas características.

3. ¿Tenderá a desaparecer este tipo de medios como consecuencia de las nuevas tecnologías e Internet? Podremos hacer un pronóstico relativamente certero gracias a la adaptación a los criterios de análisis de este estudio y a las investigaciones que en el terreno de los cibermedios auguran diversos futuros para el sector de los medios de comunicación.

\section{Estado de la cuestión}

Desde que a finales de los años ochenta hicieron su aparición en las redacciones de los medios de comunicación los primeros ordenadores -silenciosas y pulcras máquinas de escribir donde antes había acumulación de ruido y papel- la rápida evolución de las nuevas tecnologías fue provocando una transformación radicalmente sustancial en 
todos los medios de comunicación, sea cual sea el aspecto que se considere. En poco más de quince años se han sucedido cinco generaciones de medios electrónicos, desde los inicios de Internet a los dispositivos móviles (teléfonos inteligentes y tabletas) o los periódicos y los medios audiovisuales a la carta o bajo demanda.

En ese contexto, la radio y la televisión han ido a la zaga de los medios impresos, aunque su adaptación a las nuevas tecnologías distribuidas por la red ha sido mucho más rápida; tanto en el proceso de producción de la información, como en su configuración final ante el consumidor. Y ha sido así, hasta el punto de que los dos aparatos específicamente diseñados para recibir sus señales, tanto el televisor como la radio, ya no son imprescindibles para ver o escuchar la programación que producen los distintos canales de televisión o las emisoras de radio, y han sido sustituidos, en muchas ocasiones, por el mismísimo ordenador, la tableta o el teléfono.

Han eclosionado semánticamente los cibermedios, un concepto que implica un valor añadido al medio tradicional y en el que se incorpora la interactividad en su relación con los usuarios, pero salvaguardando, de momento, la esencia de cada uno de ellos. Un periódico sigue siendo de papel, por más que tenga una edición electrónica a la que se incorpora de forma instantánea todo tipo de información escrita, sonora y visual; y una televisión sigue manteniendo su programación horaria, aunque se pueda ver en su página web una serie, un informativo o un documental ya emitido. No se habla, en ambos casos, ni de ciberperiódico, ni de cibertelevisión. No ha lugar. Son portales en la red o ediciones electrónicas de unos productos que conservan su identidad y su configuración básica. El prefijo 'ciber'actúa, no tanto sobre su nombre, como sobre sus capacidades. Sin embargo con la radio ese mismo prefijo ha operado de una forma diferente. La ciberradio ha tratado de sustituir al propio medio originario, no ya de complementarlo; quiere fagocitar al medio en sí mismo, a pesar de que la evolución de la radio en Internet no haya supuesto, en contra de la creencia extendida, más que un pequeño paso en el largo camino que aún debe desarrollar para obtener definitivamente la condición de herramienta plenamente cibernética.

En algunos casos se habla -con cierta ampulosidad- de ciberradio para describir un paso evolutivo trascendente del medio, que lo es en tanto que su desarrollo se ha acompasado sin problemas a la revolución tecnológica en la que estamos inmersos, pero en realidad, partiendo del concepto de interactividad que caracteriza el presente de Internet, la radio sigue quedándose en la frontera; sigue siendo un medio unidireccional donde la participación real del oyente en su programación es casi tan escasa como lo era a finales del siglo pasado. Ciberradio sí, en tanto sean también ciberperiódico o cibertelevisión los otros dos grandes medios de comunicación de masas. Pero, a la vista de los hechos, no parece que el nivel de exigencia en cada uno de los casos sea el mismo pese a que los tres están sometidos a la misma dependencia directa de una tecnología en permanente evolución.

Por lo demás, en general se podría decir que la radio en Internet se ha convertido en un medio global, puesto que ha roto las barreras que le imponían las concesiones administrativas necesarias para estar presente en el espacio radioeléctrico. Hoy la radio, cualquier emisora de radio, puede trascender de sus fronteras territoriales sin más esfuerzo que dar cabida a su programación en la red de redes. 
¿Quiere eso decir que toda emisora de radio que difunda su señal a través de la red, teniendo en cuenta su alcance universal, es una radio global? ¿Y lo es a pesar de que no sea ese su objetivo?

La radio global, que ya existía antes de la aparición de Internet, tiene sus propias características, tanto en su configuración como en sus objetivos, que la permiten diferenciarse de la radio convencional, sea generalista o temática. No es tanto una programación determinada; sino la orientación que se hace de esa programación a una determinada audiencia. Cualquier emisión en red puede proclamar, en justicia, su alcance global, pero la ausencia de determinados elementos, como veremos, desvirtúan el concepto.

Se podría decir, por apurar esta primera consideración de carácter general, que la radio global es la que mejor ha aprovechado, probablemente, las nuevas tecnologías, adaptando sus objetivos a Internet de una forma más rápida y eficaz. Y lo ha hecho a pesar de que sigue sin ser capaz de medir realmente su impacto. No es que le importe mucho, puesto que no son emisoras que dependan de sus resultados comerciales. Con todo y con eso, de la misma forma que existen sistemas de medición, más o menos fiables, de las audiencias de los periódicos, de las televisiones y de las radios, no hay forma de saber, como tampoco la había antes de la eclosión de la radio en Internet, la incidencia real de las emisoras internacionales, que han sumado a su sistema tradicional de difusión a través de la onda corta, la potencialidad de los satélites y la de Internet, supliendo, en algún caso por completo, la antigua tecnología de emisión por los nuevos formatos digitales. También es verdad que quien lo ha hecho, quien ha optado por economizar gastos y eliminar del transporte de su señal las emisiones de onda corta, ha sido a costa de un completo desconocimiento del reguero de oyentes huérfanos que pueda haber dejado.

Hay pues una radio global muy caracterizada en la red, que es un complemento, y no la competencia directa, de otras radios con las que convive en Internet y que han logrado, utilizando las herramientas interactivas que la tecnología pone a su disposición, incrementar su capacidad para aproximarse con cierta fiabilidad a la identificación de sus respectivas audiencias.

Y por rematar las consideraciones generales, hay un último elemento coyuntural que está introduciendo una variable terminal para muchas de las empresas informativas y que tiene una especial incidencia en las que son de titularidad pública. La crisis económica y financiera ha frenado muchas iniciativas comerciales en general y, en particular en el terreno de la subvención. Ajustar el gasto contable y limitar el déficit ha significado ya el cierre de las actividades de aquellas radios internacionales que, habiendo perdido su sentido original como consecuencia de la simple evolución de la sociedad en cuyo seno nacieron, se ven ahora contempladas como algo de lo que se puede prescindir frente a problemas de otra envergadura y trascendencia social como la educación o la sanidad. El problema es que no parece que a la vuelta de unos años, cuando la economía permita recuperar los espacios que ahora se abandonan, alguien se acuerde de que allí hubo una vez, una emisora de radio con una función por cumplir. 


\section{3. ¿Radio en Internet o ciberradio?}

Entre 1927 y 1932 el dramaturgo alemán Bertolt Brecht escribe varias reflexiones sobre la radiodifusión que Werner Hecht recopila, junto a otros muchos comentarios, y edita con el título de El Compromiso Social en Literatura y Arte ${ }^{1}$. Hecht reúne aquellos textos sueltos de Brecht en una denominada Teoría de la radio que, más que un tratado científico en sí, son comentarios críticos sobre aquel extraordinario fenómeno de comunicación de masas en el que el propio Brecht intervino como guionista. Son cinco textos, alguno sin completar, que contienen reflexiones sobre la propia invención de la radio o sobre la relación entre la expresión artística y aquel aparato al que Brecht dedica específicamente un fragmento de sus comentarios titulado La radio aparato de comunicación, discurso sobre la función de la radio. Está escrito en 1932 y dice textualmente:

"La radio es un simple aparato de distribución, no hace más que transmitir [...], hay que transformarla de aparato de distribución a aparato de comunicación [...] no sólo debiera saber emitir; sino también recibir; no sólo hacer escuchar al oyente, sino hacerlo hablar; no aislarlo, sino ponerlo en relación con los demás: sería necesario que la radio abandonase su actividad como proveedora y organizara ese aprovisionamiento a partir de los mismos oyentes". (Bertolt Brecht, 1932)

Aquella visión crítica y de futuro de Brecht durmió el sueño de los justos durante mucho tiempo, puesto que la radio, por definición, ha sido hasta la aparición de Internet un medio de comunicación unidireccional. Las posibilidades de interacción del oyente han sido siempre escasas, cuando no nulas. Si se produce la participación del oyente es como actor de un determinado fragmento de la programación, puesto que es el emisor el que generosamente brinda una oportunidad que no tendría el oyente aunque quisiera. Y también es el emisor el que la limita, la dirige e, incluso, la puede llegar a condicionar. Cuando surge una oportunidad de ese tipo, es evidente que la mayoría de las personas que integran la audiencia no puede participar, y las pocas que lo consiguen lo hacen en un tiempo muy reducido y desde una posición de subordinación a los intereses de quien sea en ese momento el responsable de la emisión, que es quien marca el comienzo de la comunicación con el oyente, la orienta y la termina de acuerdo a sus intereses y a los de la programación.

La llamada radio de los oyentes es una radio en la que la participación real de los oyentes es nula. No hay interactividad, si atendemos a la definición del diccionario de la Real Academia Española que precisa el adjetivo como algo procedente por interacción, siendo esta la acción que se ejerce recíprocamente entre dos o más objetos, agentes, fuerzas, funciones, etc. (En informática, aclara la RAE, interactividad es lo que permite una interacción, a modo de diálogo, entre el ordenador y el usuario).

1 La edición manejada en este trabajo de El Compromiso Social en Literatura y Arte (1967), es la publicada por SuhrkampVerlag, en Frankfurt am Main, que se incluye aquí, y no en las referencias bibliográficas, por ser una referencia ilustrativa y no afectar a la metodología del trabajo. 
Sheizaf Rafaeli ${ }^{2}$ habla de la interactividad como una serie de intercambios de comunicaciones que implican que el último mensaje se relaciona con mensajes anteriores, a su vez relativos a otros previos. Para Bou Bauzá Guillem³ "la interactividad supone un esfuerzo de diseño para planificar una navegación entre pantallas en las que el usuario sienta que realmente controla y maneja una aplicación". Seguramente, como dice Sally J. McMillan, la interactividad es por lo general un atributo natural de la conversación cara a cara que también se produce en los entornos de comunicación digital (McMillan 2009: 37).

Desde cualquiera de esos planteamientos surge la duda sobre si las emisiones de radio a través de Internet, con el valor añadido que los portales de las distintas emisoras incorporan (valores como las noticias, los archivos, los vídeos, los blogs o los chat, y que, por lo demás, están presentes de manera casi uniforme en el resto de portales de medios de comunicación) convierten en cibernético el medio o simplemente mantienen su identidad más allá de modificar el aspecto del vehículo de transmisión adornado con otras posibilidades. Dicho de otra forma, la simple presencia de una radio en Internet, dado el carácter interactivo de la red de redes, ¿la transforma en una ciberradio?

Ángel Meseguer entiende que el grado de interactividad de las emisoras de radio españolas presentes en Internet no es demasiado elevado.

“Aún queda mucho terreno por hacer en este sentido aunque sí que se ha progresado. Está claro que no explotan todos los recursos que la red ofrece, porque esto es prácticamente imposible, pero sí se echa de menos la carencia de elementos y servicios interactivos de vital significación para establecer una relación más estrecha entre el usuario/oyente y la emisor" (Meseguer 2009: 25)

Meseguer realizó un estudio sobre la base de un modelo de análisis de elementos y servicios interactivos entre los que figuran la radio a la carta, el podcasting, los servicios sms, las alertas sms, el chat, los email, los foros de discusión, el libro de visitas, las listas de distribución y las webcams. En función de la presencia o la ausencia de alguno de esos servicios en los portales de las emisoras de radio midió el grado de interactividad de 2.500 webs para llegar a la rotunda conclusión de que aún resta mucho por hacer en el periodismo radiofónico en Internet. Es más, entiende simple y llanamente que no existe ninguna emisora de las analizadas que pudiéramos definir como modelo de ciberradio.

2 Sheizaf Rafaeli investigador israelí, estudioso de la comunicación a través de los ordenadores, científico informático y columnista de periódicos. Es profesor y decano de la School of Management (escuela de graduados en administración de empresas) de la Universidad de Haifa y, además, director del Centro para la Investigación Sagy Internet (anteriormente conocido como el Centro para el Estudio de la Sociedad de la Información). A finales del siglo pasado fue jefe del área de sistemas de información en la Escuela de Graduados de Negocios de la Universidad Hebrea de Jerusalén.

3 El Dr. Bou Bauzá Guillem. dirige el Laboratorio de Comunicación Interactiva de la Universidad La Salle, de Barcelona. 
Parece bastante evidente que los oyentes aún no pueden desempeñar su nuevo/viejo objetivo en la sociedad de la información que no es otro que el de dejar de ser receptores para convertirse en diseñadores y actores de las ofertas. Ni siquiera lo es el denominado periodismo ciudadano, aunque entrar en ese terreno es perderse en una disquisición conceptual que lleva a otros terrenos. En todo caso, es difícil que se alcancen los objetivos mientras no exista una independencia real del medio convencional. Que la radio ha ganado con el desarrollo de Internet parece obvio, aunque sólo sea por el hecho de ofrecer muchas más posibilidades de actuación, más allá de trasladar sus emisiones a la red. ¿Habría que considerar la radio convencional y la radio en Internet como dos medios diferentes? La radio convencional utiliza el sonido como herramienta comunicativa y la radio en Internet no sólo puede utilizar el sonido, sino que también pone a disposición de los oyentes las imágenes, los textos y otros valores añadidos. Por lo tanto sus características y sus soportes son diferentes y deberían considerarse como dos medios distintos. Pero de ahí a creer que la radio por Internet es un cibermedio hay todavía mucha distancia.

Queda mucho margen de evolución para la radio en Internet y se irá produciendo conforme se vayan descubriendo nuevas formas de relación del usuario con la red, que serán las que produzcan finalmente la verdadera interactividad del medio. El camino está ahí; no es otro que la radio a la carta; que el oyente pueda seleccionar lo que quiere escuchar y en qué momento, sin ningún tipo de limitaciones temporales; que el ciberoyente sea el diseñador de su propia oferta, que vendría a ser, en lo que a este medio se refiere, uno de los paradigmas de la sociedad de la información.

\section{Internet y la radio global. El caso de Radio Exterior de España}

La radio en Internet ha roto la barrera física que a la radio convencional le marca la adjudicación administrativa de un lugar determinado en el espacio radioeléctrico. Todas las radios se han adentrado en un universo global en el que las fronteras de la radio tradicional, sucesivamente la local, la regional, la nacional y la internacional, ya no existen. Si por definición, todo cuanto entra en Internet se convierte en algo universal, la radio en la red alcanza ya la consideración de global, aunque otra cosa es que un portal de radio se plantee realmente la cobertura comunicativa e informativa de todo el ámbito geográfico que pueda alcanzar.

Siendo así, más allá de los dos modelos clásicos, la radio convencional y la radio temática, existe un concepto de radio global que Internet no ha hecho más que reforzar, otorgándole, en la práctica, características diferenciales.

Es evidente que toda emisión radiofónica, por el mero hecho de estar en la red, alcanzaría ya la consideración de global, aunque ese concepto, en el caso de la radio, tiene unas connotaciones específicas.

La onda corta, también conocida como SW (del inglés shortwave) o HF (highfrequency), es una banda de radiofrecuencias comprendidas entre los 2.300 y los 29.999 $\mathrm{kHz}$ en la que empezaron a transmitir, y todavía transmiten, las denominadas emisoras de radio internacionales. Son dos, básicamente, las características que definen un modelo dirigido de forma intencionada a audiencias, en principio, muy específicas. Son todas ellas emisoras de titularidad pública, con dependencia directa, orgánica y funcio- 
nal, según el modelo, del gobierno o del parlamento; en consecuencia, la procedencia de las inversiones económicas necesarias para mantenerla y desarrollarla es de carácter público. Y, segunda característica, todas ellas transmiten su programación o parte de su programación en varios idiomas, con el objeto de extender su área de influencia.

Las radios internacionales vivieron su época dorada a mediados del siglo pasado, durante la Segunda Guerra Mundial y la posterior Guerra Fría, como una herramienta más de propaganda o de información veraz, según se mire, en países sometidos a dictaduras, dada la capacidad de la onda corta para superar las barreras de la distancia o el hecho de trabajar en un espectro que evita cualquier tipo de interferencia o censura. Con el paso de los años y de las conquistas progresivas de los espacios de libertad en muchas zonas del mundo, la práctica totalidad de las radios internacionales han ido adaptando su orientación programática a los nativos emigrantes en otros países, a los profesionales que tienen que pasar largas temporadas fuera de su país o incluso a la promoción del turismo y a la mejora de la imagen externa.

\subsection{Orígenes y evolución de Radio Exterior de España}

Radio Exterior de España, REE, fue concebida en sus orígenes como la emisora que representaba 'la voz de España' en el exterior. El 15 de marzo de 1942, Radio Nacional de España, RNE, inició sus emisiones radiofónicas en onda corta para Europa y América Latina. Inicialmente en castellano y posteriormente en inglés, francés, alemán, italiano, portugués y árabe. Eran los tiempos de la dictadura franquista y el guion radiofónico se ajustaba a los imperativos de propaganda del régimen, en abierta batalla con las emisiones en castellano de otras emisoras internacionales que contaban lo que ocurría realmente en España, no lo que dictaban los sucesivos gobiernos de Franco.

En enero de 1978, con la llegada de la democracia, se constituyó formalmente REE como emisora singular dentro de la red de emisoras de RNE. Desde el principio, REE mantuvo el criterio de cubrir radiofónicamente los cinco continentes y de emitir en gran cantidad de lenguas, con la única tecnología entonces conocida, la onda corta. A lo largo de los años, REE fue ampliando sus medios técnicos y sus recursos humanos, llegando a alcanzar en algún momento las 300 personas en plantilla ${ }^{4}$.

En la década de los 80 se iniciaron emisiones en catalán, gallego y euskera. Se produjeron también cambios en las lenguas extranjeras de emisión, desapareciendo algunas (italiano o alemán) e incorporando otras (ruso y sefardí). Y ha sido, tradicionalmente, muy cuidadosa con los intercambios culturales, en especial con centros e instituciones educativas de Iberoamérica, donde se difunden algunos de sus programas más emblemáticos.

4 En la actualidad REE dispone de un centro emisor en la localidad de Noblejas (Madrid) y otro en Cariari (Costa Rica) y de un remisor "rele" mediante convenio en Pekín. El centro de Noblejas ha experimentado recientemente un importante proceso de modernización técnica. También se utilizan diferentes satélites para la difusión intercontinental de sus programas. La plantilla tipo de Radio Exterior de España, contando todas las categorías profesionales, es de 70 personas. 
En los últimos años REE ha hecho un esfuerzo de innovación tecnológica. Desde octubre del 2007 se emite para Europa mediante el sistema digital $\mathrm{DRM}^{5}$, que ha permitido mejorar la calidad, cobertura y estabilidad de la señal, y distribuye su programación en Internet, tanto en directo como a través de todos los podcast de todos sus programas, esfuerzo sin igual en comparación con la mayoría de las emisoras internacionales.

En sus orígenes, REE se desenvolvió en un contexto social y tecnológico muy diferente al actual y caracterizado básicamente por la importante presencia de la inmigración española de primera y segunda generación en Europa y América y la presencia temporal o permanente en el extranjero de determinados colectivos españoles como los marineros y pescadores o los misioneros.

Hoy en día esa realidad ha cambiado profundamente y muy en especial en lo que se refiere a las formas tecnológicas de difusión audiovisual. También por el hecho de haber dejado de ser un país de emigrantes, pasando a ser un país con una fuerte presencia de extranjeros y a la evidente integración de la emigración española de segunda y tercera generación que se ha mantenido en los países de acogida. Es verdad que la actual crisis financiera y económica vuelve a transformar esa configuración de país y son muchos los inmigrantes que regresan a sus naciones de origen ante la falta de oportunidades en España, y casi tantos los españoles que buscan en el exterior los horizontes profesionales que aquí no encuentran. A la espera de que se confirme o no esa tendencia observada, podría decirse que los colectivos españoles que permanecen de forma temporal en el extranjero tienen un perfil muy diferente a los del siglo pasado y unos hábitos de acceso a la comunicación audiovisual en todo caso bien distintos (turistas, estudiantes, profesionales o empresarios en viajes de trabajo, cooperantes, fuerzas armadas en misiones de paz). Y por lo tanto la programación de REE ha ido adaptándose a esa nueva realidad de los oyentes españoles en el extranjero y al interés que pueda despertar la marca España en el exterior.

El reto más importante al que se han enfrentado en general las emisoras internacionales, y entre ellas REE, es la aceleración del cambio tecnológico audiovisual, la creciente implantación de Internet y la reducción de los oyentes por onda corta. Un reto que se agiganta, si cabe, en un panorama de crisis económica y teniendo en cuenta que una parte sustancial de los costes de emisión, en muchos casos,se derivan de las necesarias instalaciones para la transmisión por onda corta; un asunto estratégico a pesar de que el mercado de los aparatos de radio de onda corta está desapareciendo.

Emitir a través de la onda corta en el caso de algunos ámbitos territoriales (en alguno de ellos el Estado español tiene intereses estratégicos, casos del Magrebo Centroamérica) es la única forma de alcanzar a una audiencia que no tiene ningún tipo de

${ }^{5}$ DRM, Digital Radio Mondiale (Radio Digital Mundial) es un conjunto de estándares de radiodifusión digital desarrollado por el consorcio Digital Radio Mondiale, usando las frecuencias y concesiones otorgadas a las transmisiones de amplitud modulada (AM) y de frecuencia modulada (FM). Ningún país es propietario de este sistema de radio digital, que ha sido desarrollado e implementado por el consorcio que integran Radio France Internationale, TéléDiffusion de France, BBC WorldService, Deutsche Welle, Voice of America, Telefunken (Transradio) y Thomcast (ThomsonSA). 
acceso a Internet. De hecho las grandes emisoras públicas europeas, y entre ellas REE, mantienen -de momento- su difusión en onda corta y cada seis meses se producen encuentros internacionales para la coordinación de las frecuencias (las demandas de frecuencia de países como los nuevos Estados procedentes de la extinta Unión Soviética ha aumentado en las últimas reuniones). Seguramente no está de más señalar que la utilización de las frecuencias de onda corta requiere una planificación internacional compleja y que hasta ahora, hasta la eclosión de la crisis económica y financiera, si se perdía su adjudicación por falta de ocupación o se renunciaba a ella era prácticamente imposible recuperarla porque inmediatamente pasaba a ser ocupada por otra emisora. La crisis vuelve a modificar el sistema y son muchas las frecuencias en onda corta que están siendo abandonadas por las emisoras internacionales como consecuencia del alto coste. Sólo el suministro eléctrico del complejo de REE en el centro emisor de Noblejas cuesta 3 millones de euros anuales.

Hasta hace muy pocos años, las emisoras emblemáticas no se limitaban a la difusión primaria a través de la onda corta, sino que la utilizan como transporte de gran alcance para posteriormente, sobre el terreno, ampliar su cobertura, minimizando su escasa calidad radiofónica y garantizando su recepción por el oyente local, puesto que se reemitía mediante otros transmisores de onda media o frecuencia modulada propios o en convenios de colaboración. Esa mecánica ha desaparecido en la práctica puesto que la implementación de las emisiones en Internet ha hecho derivar hacia la tecnología IP todo el caudal de señales que existía, automatizando además el proceso y preservando, fundamentalmente, la calidad de la fuente original.

La adaptación de Radio Exterior de España a las tecnologías digitales se ha producido casi en paralelo a la de la empresa titular, Radio Nacional de España. Los procesos de adaptación del software de emisión a través de Internet han sido exactamente los mismos, como también han crecido en paralelo otros elementos como los blogs o los correos electrónicos de los diferentes programas. Con todo y con eso, las prioridades estratégicas de las sucesivas direcciones de RTVE han ido discriminando su presencia en el portal de la Corporación en beneficio del protagonismo del canal principal de la radio pública y sólo en un aspecto específico, cuando dio comienzo la digitalización de las señales, fue REE por delante de RNE en la posibilidad de acceso a los podcast de los programas, siendo, como eran, un elemento de demanda específica por parte de su audiencia. Ahora mismo, la capacidad de acceso a cualquier podcast de cualquier programa de cualquier canal de los seis que tiene REE es absoluta e inmediata para todos los usuarios.

\subsection{La audiencia de Radio Exterior de España}

¿Quién es la competencia de REE? Parece una pregunta de Perogrullo, si se tiene en cuenta que al igual que REE, el resto de emisoras internacionales comparten el mismo objetivo en las mismas áreas de influencia: todos quieren 'vender' país. Con mayor o menor acierto; con más o con menos medios; con un lenguaje más o menos adaptado a las nuevas tecnologías.

En general, el paradigma de la radio internacional es la BBC WorldService, que se ha ganado a pulso los galones, sobre todo si se tiene en cuenta la distancia en el esfuerzo presupuestario del que sigue gozando en comparación con los de las otras gran- 
des emisoras globales ${ }^{6}$. Como contrapunto, REE ha sufrido especialmente las consecuencias del expediente de regulación de empleo al que se sometió la corporación de RTVE en 2008, reduciendo considerablemente la plantilla de la emisora, que es en la actualidad de 70 personas. Su programación, sin embargo, sigue siendo valorada de forma positiva. Con certeza es una valoración más cualitativa que cuantitativa y basada en la comunicación a iniciativa propia de sus oyentes, ya que por razones evidentes nunca ha sido posible hacer una aproximación cuantitativa a los niveles reales de audiencia de la emisora.

La BBC International o Servicio Mundial de la BBC, incorpora en sus balances anuales estimaciones de audiencia que la llevan a asegurar que sus emisiones alcanzan a 180millones de personas. No facilita ningún dato empírico para poder contrastarlo. Resultaría extraordinario que algún día lo hiciera porque si ya es difícil otorgar fiabilidad a los estudios demoscópicos que se realizan en España, y que son pagados por las propias empresas de comunicación que compiten por el mercado publicitario, alcanzar con un encuestador a un oyente que trabaje en el altiplano peruano o que navegue en el océano Índico resulta imposible hasta para la imaginación más calenturienta.

Hasta el presente REE había realizado una estimación del alcance de sus emisiones, y por lo tanto de su audiencia, sólo mediante la correspondencia postal de los oyentes. Lógicamente ha incorporado ya el correo electrónico, como elemento de respuesta. No es, evidentemente, el mejor método demoscópico, aunque de momento es el único posible, más allá del número de podcast de programas que se descarguen. No se puede medirla audiencia de una radio global de una forma fiable. Hay que convencer al potencial oyente, en este caso de REE, para que se tome la molestia de escribir a la emisora, bien un correo postal o bien un correo electrónico, y contestar a alguna de las preguntas que se le puedan formular llegado el caso. Por norma general, se incluyen promociones en la programación incentivando la participación. Pero, ¿Cómo conseguirlo realmente? ¿Cómo obtener una aproximación a la audiencia más allá de las respuestas puntuales de la audiencia a determinados programas?

\subsection{La encuesta}

REE puso en marcha, a mediados del año pasado, una forma clásica y un tanto sesgada, para hacer una primera base desde la que poder construir en el tiempo, a través de distintas oleadas, un perfil de su audiencia o de su alcance. Para ello recurrió a un recurso relativamente sencillo: un sorteo de algo que capte el interés de parte de la potencial audiencia, siendo consciente de que ese interés no es el mismo en función de muchas variables: formación, ocupación, ingresos, localización, etc.

Hasta finales de mayo del año pasado, la correspondencia recibida en REE, salvo excepciones, era de tipo genérico; oyentes que preguntaban por detalles de la programación, que solicitaban material de promoción, que enviaban informes de recepción o que querían saber las frecuencias en las que emite en los lugares a los que viajan. No era, en general, una correspondencia sobre el contenido de cada uno de los programas de la emisión o sobre la emisión en su conjunto.

${ }^{6}$ A finales del año pasado, el parlamento británico recortó casi en un cuarto (2.500 millones de libras) el presupuesto global de la BBC, sometida, por lo demás, a un severo ajuste de plantilla. 
Se pensó que ese caudal de datos se podría reconducir hacia un mapa aproximado de la audiencia incentivando respuestas a preguntas sencillas, a cambio de la participación en un sorteo de cinco aparatos de radio de onda corta, además de otros elementos promocionales como premios menores. Se arbitró un plazo de un mes para recibir las respuestas, a través del correo electrónico o del correo postal, y se insertó una cuña promocional con la convocatoria a lo largo de la programación y en las diferentes lenguas en las que emite.

El resultado fueron 1.255 respuestas desde todos los rincones del mundo, de un oyente tipo que mayoritariamente es español o cubano y que escucha la programación en la lengua española y a través de la onda corta aún que, paradójicamente, contesta fundamentalmente a través del correo electrónico, lo que implica que accede a Internet. Tiene entre 23 y 50 años, está pendiente de la programación entre una y dos horas diarias y le es indiferente la franja horaria de escucha. Hay oyentes con ganas de participar en un concurso en prácticamente todos los rincones del planeta y, particularmente en Cuba, hay un interés muy llamativo por la programación de REE (o por los aparatos de radio, que seguramente también).

La distribución de las 1.255 respuestas, de las que 318 llegaron a través del correo postal y 937 por correo electrónico es la que sigue:

¿En qué idioma escucha la programación? Contestaron que en español 1.148 oyentes, lo que representa el 91,47 del total. En inglés, 41; en francés, 24; en árabe, 21; en ruso, 3 ; en portugués, 15 y en sefardí, 3. ¿A través de que medio escucha la programación? A través de la onda corta lo hacen 877 de las personas que contestaron, un 69,88 por ciento. Internet fue utilizado por 366 ; los podcast por 9 y el satélite por 3 de los oyentes que querían participar en el concurso. Tiempo medio de escucha de la programación: menos de una hora, 421 respuestas; entre una y dos horas, 769; más de dos horas, 65. Horario de escucha, medido en Coordinated Universal Time (UTC, Tiempo Universal Coordinado). Entre las $00 \mathrm{~h}$. y las 06, 344 respuestas; entre las 06 horas y las 12, 389; entre las 12 y las 18 horas, 367; y entre las 18 y las 24 horas, 155.

\subsection{Cuadros de las respuestas de le encuesta \\ 4.4.1. Cuadro mundial}

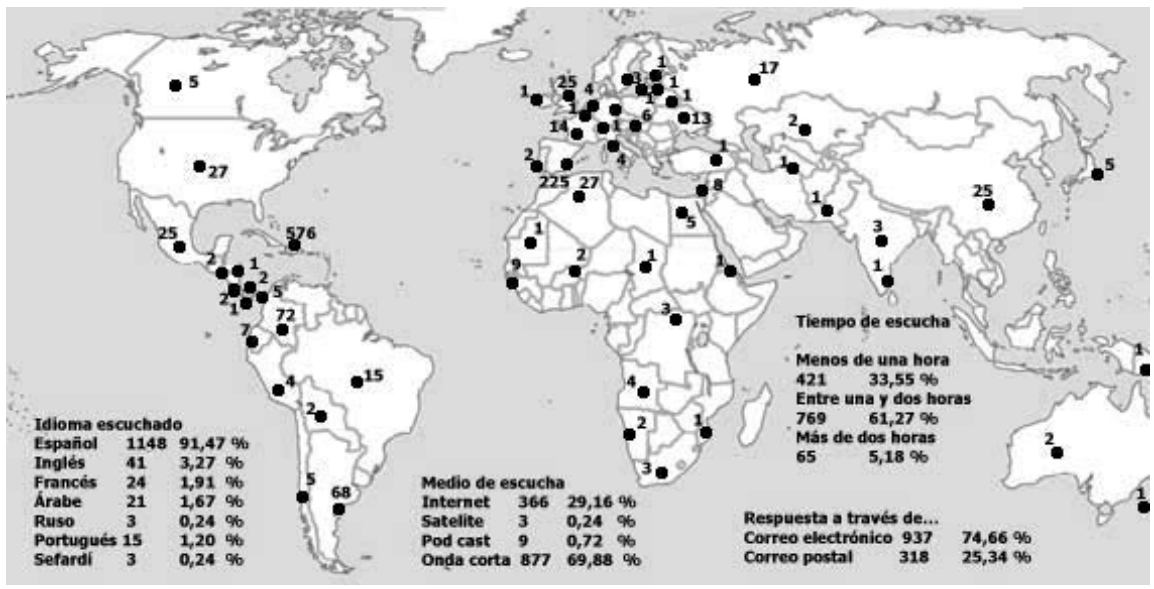




\subsubsection{Cuadros de las respuestas por continentes y países}

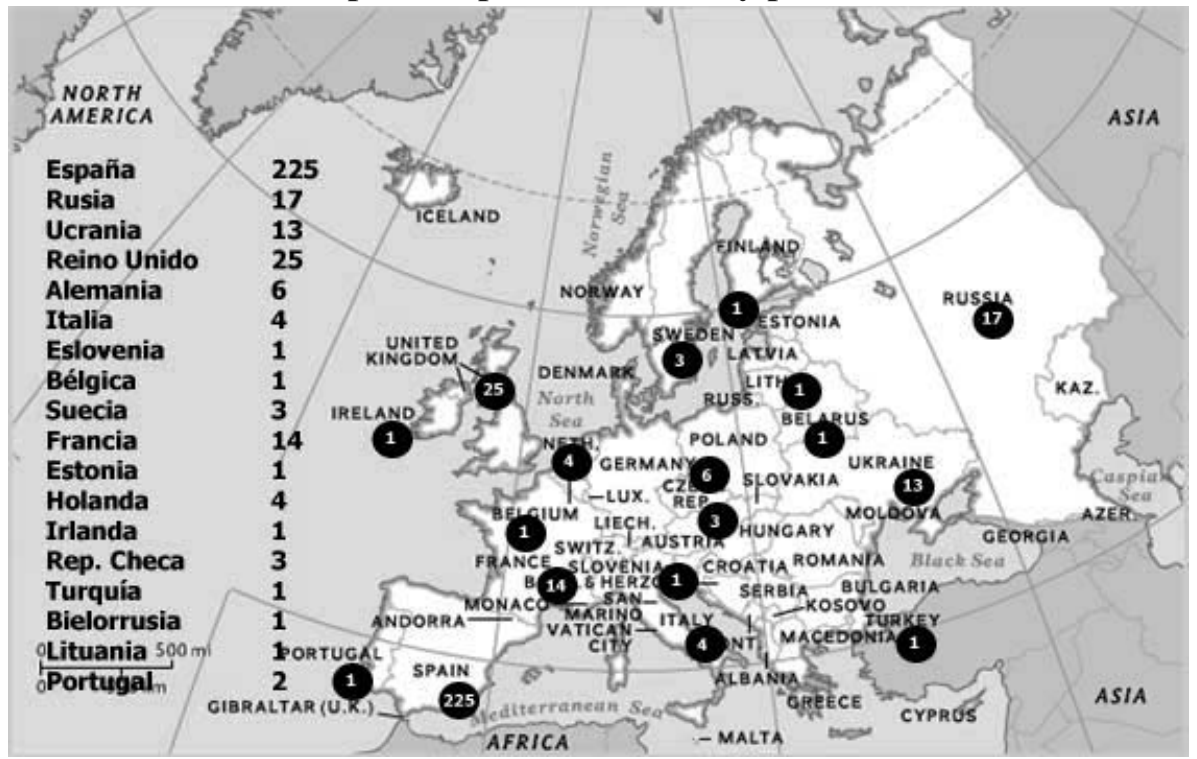

Europa: 316 respuestas $(23,76 \%$ del total)

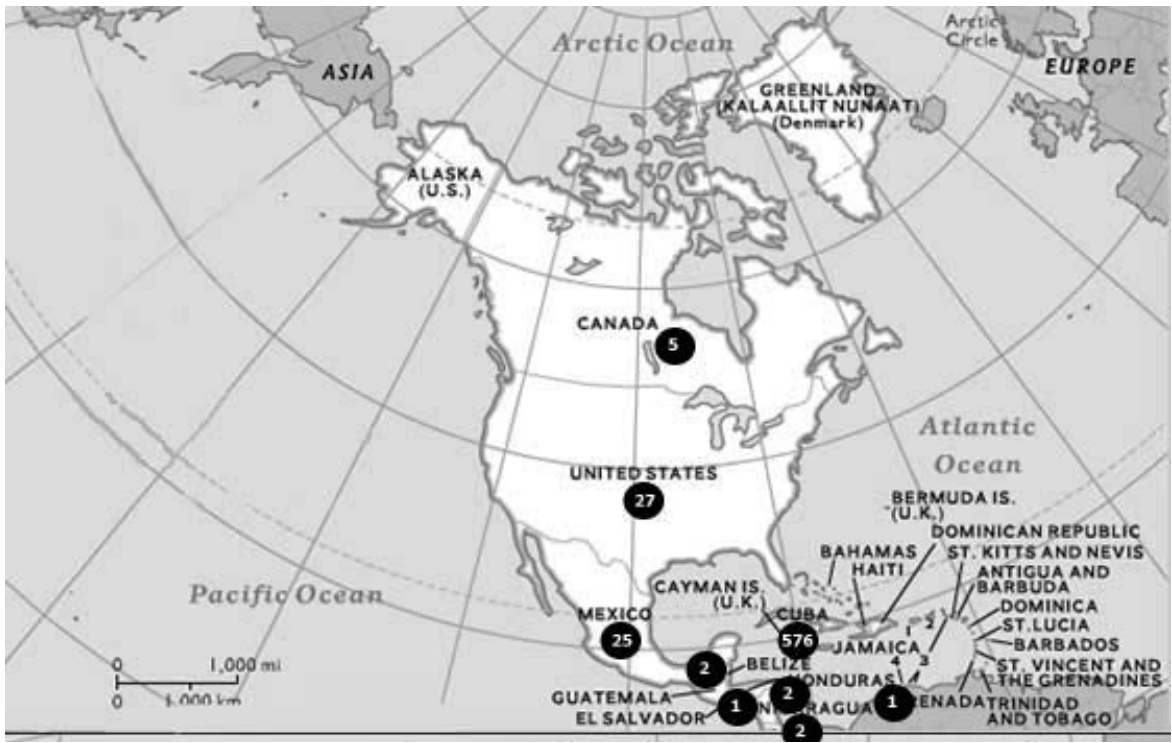




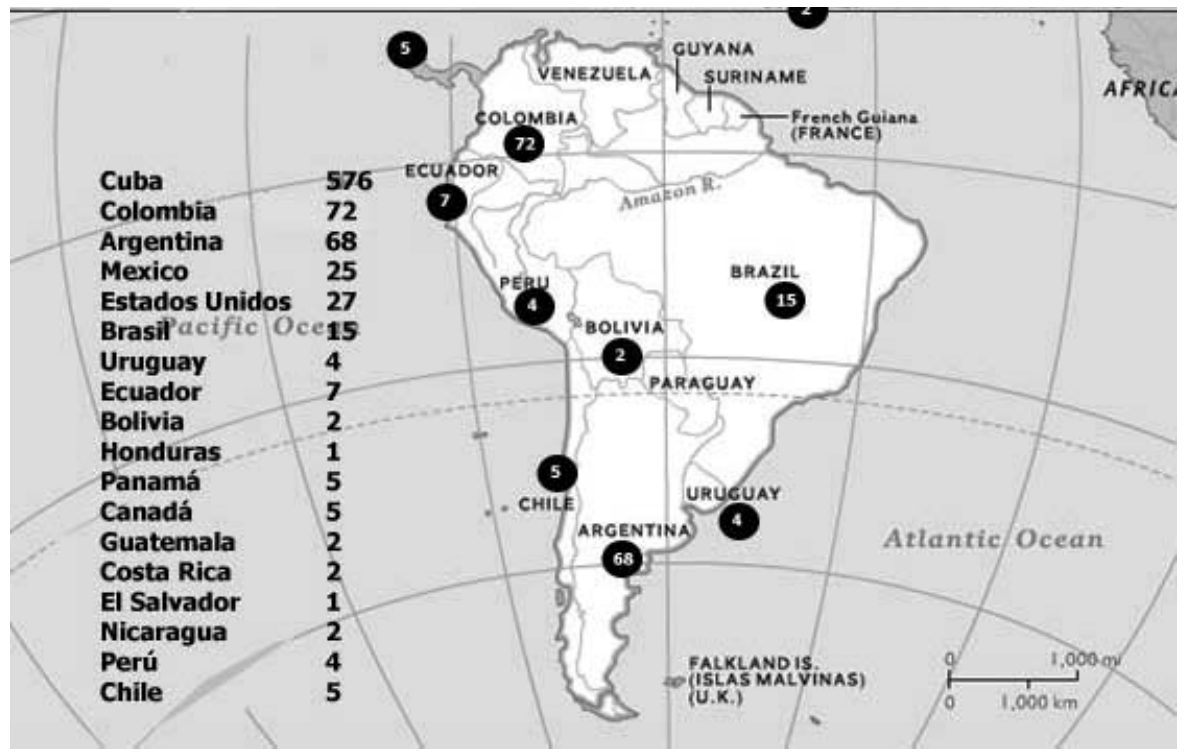

América: 823 respuestas $(65,58 \%$ del total $)$

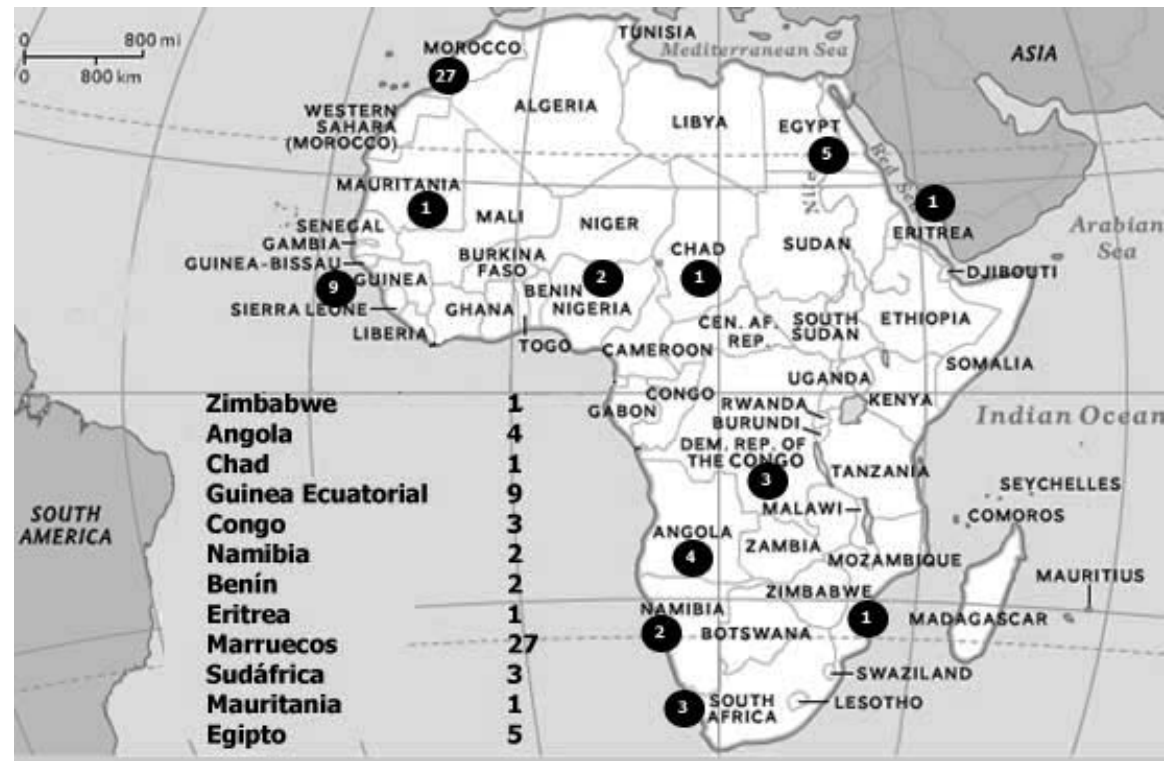

África: 59 respuestas $(4,70 \%$ del total $)$ 


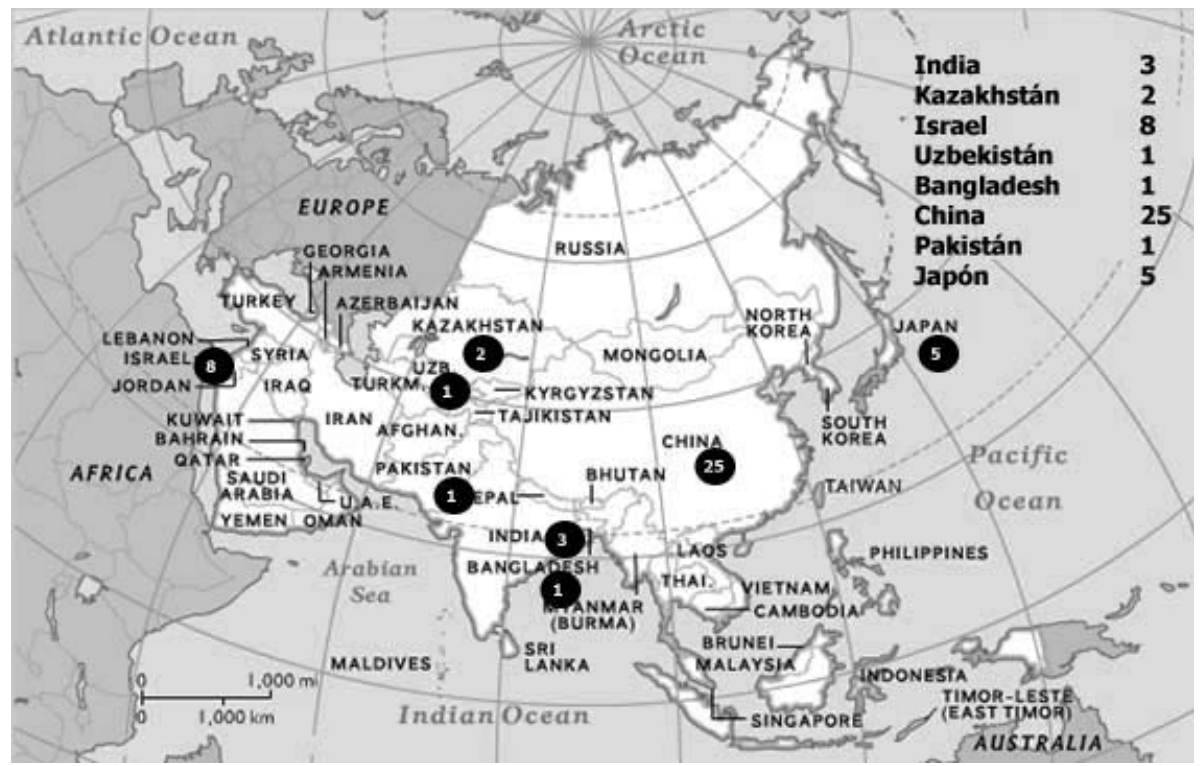

Asia: 47 respuestas $(3,75 \%$ del total $)$

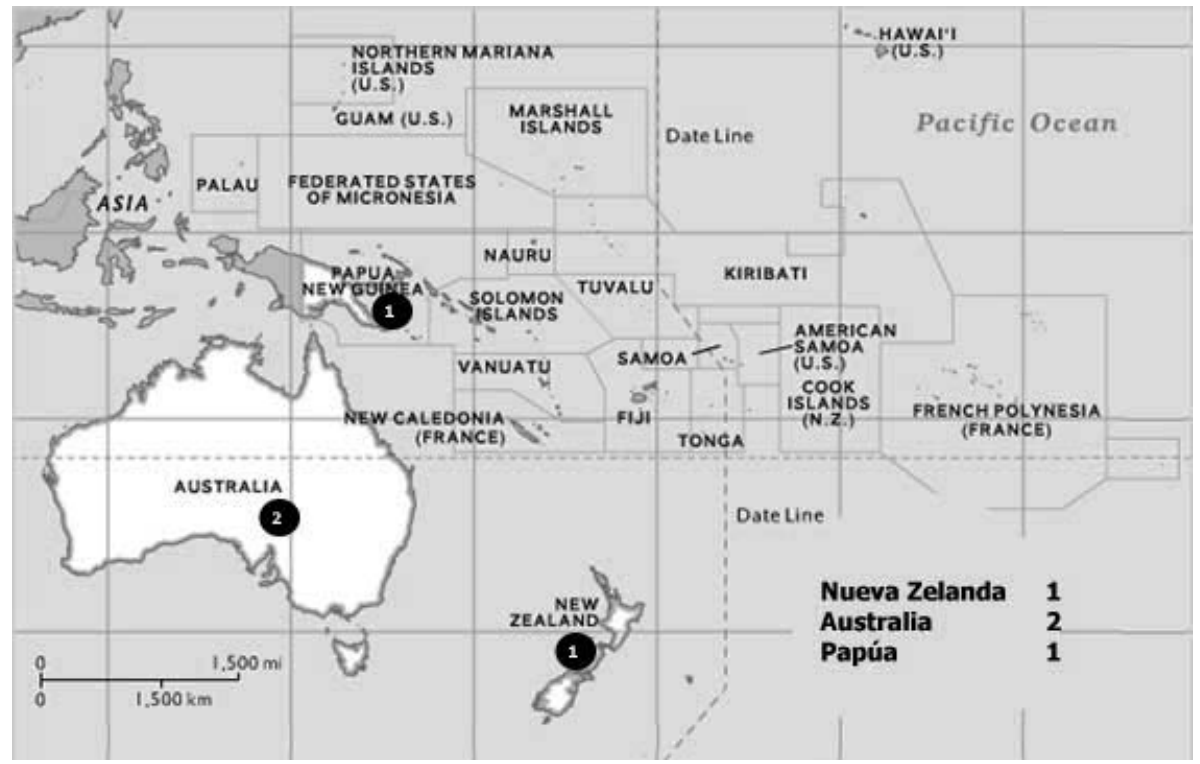

Oceanía: 3 respuestas $(0,24 \%$ del total $)$

\section{Conclusiones}

Después de esta exposición panorámica del estado de la radio global y su competencia en Internet podemos tratar de dar respuesta a los interrogantes de investigación 
planteados en la presentación del trabajo. Algunas de esas respuestas se pueden extraer claramente del objeto investigado por los datos ofrecidos a lo largo del desarrollo del tema, que trata de ser lo más académico posible y estar basado también en la opinión tanto científica de los estudiosos de la cuestión como de los profesionales del mundo audiovisual implicados. Otras respuestas las obtenemos del análisis, planteado en la metodología, gracias a la encuesta realizada por REE y expuesta en el punto 5 de este trabajo. De forma que, ordenando esos interrogantes de investigación podríamos concluir, numerándolos según nos habíamos planteado, lo siguiente:

1. Tecnología vs financiación. ¿Tenderá a desaparecer este tipo de medios como consecuencia de las nuevas tecnologías e Internet? La crisis mundial en la que seguimos envueltos hace muy difícil la continuidad de determinados servicios públicos, prescindibles cuando lo que está en juego son los mismos pilares del Estado del bienestar. Las inversiones necesarias para el mantenimiento de las instalaciones de onda corta, unida a la exponencial evolución de las nuevas tecnologías de la comunicación, hace impensable la supervivencia de un modelo tan excesivamente costoso como poco rentable, más si cabe cuando es difícil medir su alcance cuantitativo y cualitativo. Se podría utilizar para Radio Exterior de España el mismo viejo chascarrillo que circula en algunos rincones malintencionados de RTVE y que asegura que resulta más barato regalar los discos de música que quieran los oyentes de Radio Clásica que mantener sus emisiones. Más allá del futuro que promete la evolución imparable de las nuevas tecnologías, está la misma existencia de servicios públicos que se están ya abandonado y que seguramente será improbable, si no imposible, que se recuperen en un horizonte más o menos cercano.

2. ¿Ha conseguido Radio Exterior de España realizar la adaptación que exige Internet a un cambio radical en la nueva forma de hacer el periodismo? Aunque las radios de ámbito internacional existentes, como es el caso de Radio Exterior de España, han encontrado una dura competencia en el desarrollo de Internet como medio global, ciertamente han sabido adaptarse a los nuevos tiempos aprovechando y conservando las antiguas fórmulas de distribución de su señal (hasta cuando se ha podido) y complementándolas gracias a su adaptación y entrada paralela en el mercado de la red de redes.

3. ¿Cuál es la tipología del público objetivo de Radio Exterior de España? Podremos atisbar lejanamente cómo es el oyente de este tipo de medio, y, gracias a nuestra herramienta metodológica, hacer una descripción del perfil tipo de audiencia que utiliza este tipo de radio, tanto desde el punto de vista del servicio público como desde el objetivo de información y entretenimiento que se propone cualquier medio de comunicación de estas características. En todo caso la ausencia de las herramientas necesarias para implementar un procedimiento empírico, tanto financieras como tecnológicas, hace imposible una precisión rigurosa, quedando tan solo una estimación, seguramente subjetiva y/o interesada.

Ello nos llevaría a pensar que este estudio podría suponer un inicio de futuras investigaciones más profundas relativas a este sector particular de los medios audiovi- 
suales. Aunque podamos concluir que no es un medio rentable, o fácilmente rentabilizable, deberíamos proponernos aportar nuevas soluciones para poder rentabilizar una estructura tecnológica y profesional que, aunque costosa, tiene abiertas muchas posibilidades de desarrollo. El caso de REE es un caso particular afectado por las características particulares de empresa pública, al igual que la mayoría de las emisoras globales mundiales, pero que en España está pasando por una etapa más crítica que en otras regiones del mundo. Por supuesto que está es una labor en la que debe implicarse toda la sociedad, contando con la Administración, el público y, sobre todo, los profesionales del medio.

\section{Referencias bibliográficas}

BRECHT, Bertolt (1927-1932): "Teorías de la radio. La radio: ¿un descubrimiento antediluviano?" (2003) Revista de Economía Política de las Tecnologías de la Información y Comunicación. http://www.eptic.com.br. [Consultado: 20-12-2011]

MCMILLAN, Sally (2009): "Exploring models of interactivity from multiple research traditions: users, documents, and systems". Tennessee, EE.UU., University of Tennessee Pbl.

MESEGUER CONESA, Ángel (2009): La radio del siglo XXI, un medio interactivo. Euroeditions. Fundación Europea para la Sociedad de la Información y la Administración Electrónica. 